University of Nebraska - Lincoln

DigitalCommons@University of Nebraska - Lincoln

Agronomy \& Horticulture - Faculty Publications

Agronomy and Horticulture Department

$12-1979$

\title{
Cyanogenesis in Indiangrass Seedlings
}

Francis A. Haskins

University of Nebraska-Lincoln, fhaskins@neb.rr.com

H. J. Gorz

Kenneth P. Vogel

University of Nebraska-Lincoln, kvogel1@unl.edu

Follow this and additional works at: https://digitalcommons.unl.edu/agronomyfacpub

Part of the Plant Sciences Commons

Haskins, Francis A.; Gorz, H. J.; and Vogel, Kenneth P., "Cyanogenesis in Indiangrass Seedlings" (1979). Agronomy \& Horticulture -- Faculty Publications. 280.

https://digitalcommons.unl.edu/agronomyfacpub/280

This Article is brought to you for free and open access by the Agronomy and Horticulture Department at DigitalCommons@University of Nebraska - Lincoln. It has been accepted for inclusion in Agronomy \& Horticulture -Faculty Publications by an authorized administrator of DigitalCommons@University of Nebraska - Lincoln. 


\title{
Cyanogenesis in Indiangrass Seedlings ${ }^{1}$
}

\author{
F. A. Haskins, H. J. Gorz, and K. P. Vogel ${ }^{2}$
}

\begin{abstract}
In a study of seedlings of 72 entries representing 39 species, 14 genera, and 2 tribes of grasses, only entries of the genus Sorghastrum were found to contain the cyanogenic glucoside, dhurrin $[(S)$-p-hydroxymandelonitrile $\beta-D$-glucopyranoside]. Dhurrin was found in seedlings of each of the 10 entries of indiangrass [Sorghastrum nutars (L.) Nash] and the three entries of $S$. pellitum.

Seedlings of five indiangrass cultivars were assayed for dhurrin concentration. Levels expressed as HCN potential (HCN-p) ranged from about $900 \mathrm{ppm}$ for 'Holt' to about $1,200 \mathrm{ppm}$ for 'Llano' and 'Oto'.

Further studies with Oto seedlings indicated that first leaves were higher and more uniform in HCN-p than were other portions of the shoot, but all shoot portions contained dhurrin. Seedling roots also contained dhurrin, but the HCN-p of roots was appreciably lower than that of shoots.

Spectral evidence indicated that dhurrin was present in extracts of leaves of tillers harvested from field-grown plants. Dhurrin was not detected in all such tillers, however. Indiangrass tiller extracts contained more in. terfering substances than seedling extracts, in agreement with previous observations on Sorghum seedlings.
\end{abstract}

Additional index words: Dhurrin, Prussic acid, Cyanide, Sorghastrum nutams (L.) Nash.

CYANOGENESIS, the ability of organisms to produce hydrocyanic acid (HCN), is widespread in the plant kingdom. This ability has been reported in approximately 1000 plant species, but the identity of the cyanogenic compound(s) has been established for less than 100 of these species (2). The first cyanogenic compound isolated from a member of the Gramineae was dhurrin $[(S)$-p-hydroxymandelonitrile $\beta-D$ glucopyranoside] (4), which was isolated from Sorghum plants in 1902 by Dunstan and Henry (3). Sorghum remained the only grass genus in which the occurrence of dhurrin has been shown conclusively (

\footnotetext{
${ }^{1}$ Contribution from AR-SEA-USDA and the Nebraska Agric. Exp. Stn., Lincoln NE 68583. Published as Paper No. 5761 Journal Series, Nebraska Agric. Exp. Stn. The work reported was conducted under Nebraska Agric. Exp. Stn. Project No. 12088 . Received 10 May 1979.

${ }^{2}$ Foundation professor of agronomy; supervisory research geneticist, AR, SEA, USDA and professor of agronomy; and research agronomist, AR, SEA, USDA and assistant professor of agronomy; Univ. of Nebraska, Lincoln, respectively.
}

until recent work from this laboratory (6) established that dhurrin occurred also in seedlings of indiangrass [Sorghastrum nutans (L.) Nash]. Indiangrass, a warm season, tall, perennial species, is widely distributed in the United States, and is a common constituent of the hay meadows, pastures, and rangelands of the eastern Great Plains (8).

When hydrolyzed, dhurrin yields HCN, glucose, and $p$-hydroxybenzaldehyde $(p-\mathrm{HB})$ in equimolar amounts. The results of Akazawa et al. (1) and of Mao and Anderson (10) suggested the feasibility of using the concentration of $p-\mathrm{HB}$ in hydrolyzed extracts of Sorghum tissues as a measure of HCN-potential (HCN-p) of the tissues. Subsequently, the development and use of a simple and rapid procedure was described in which the assay of $p$-HB served as the basis for determining the HCN-p of Sorghum seedlings (5). In this procedure, dhurrin is extracted and simultaneously hydrolyzed by autoclaving the first leaves of young seedlings in water. The extract is then diluted in alkali, and the absorbance of the solution is read at $330 \mathrm{~nm}$, the absorption maximum of $p-\mathrm{HB}$ in alkaline solution. $H C N$-p values are calculated from the $\mathbf{A}_{\mathbf{3 3 0}}$ readings. The spectra of numerous Sorghum seedling extracts were scanned between 250 and $400 \mathrm{~nm}$ to verify the validity of using the $A_{330}$ value as a measure of $p$-HB concentration $(5,7)$.

It was the purpose of this study to screen seedlings of a number of grasses for the presence of dhurrin, and to determine the HCN-p of different parts of indiangrass seedlings of different ages. Preliminary assays of HCN-p in tillers of field-grown plants also were conducted.

\section{MATERIALS AND METHODS}

Seed Sources. A list of all genera included in the study, as well as the numbers of species and entries within each genus, is shown in Table 1. Seed of most of the entries was obtained from Dr. W. R. Langford, Southern Regional Plant Introduction Station. The Euchlaena seed was supplied by Dr. G. W. Beadle, Univ. of Chicago; the Zea seed by Dr. W. A. Compton, Univ. of Nebraska; and the Erianthus seed by Dr. Michael Mc Crary, Soil Conservation Service National Plant Materials Center, Beltsville, Md. Seed of 'Oto' indiangrass, the cultivar used in most of these studies, was obtained from the Foundation Seed Division, Univ. of Nebraska.

Growth of Seedlings. All entries except Zea and Euchlaena 
Table 1. Grasses tested by the spectrophotometric method for the presence of dhurrin in seedling leaves. Classification is according to Hitchcock and Chase (8).

\begin{tabular}{llcc}
\hline Tribe & Genus & $\begin{array}{c}\text { No. of } \\
\text { species tested }\end{array}$ & $\begin{array}{c}\text { No. of } \\
\text { accessions }\end{array}$ \\
\hline Andropogoneae & $\begin{array}{l}\text { Andropogon } \\
\text { Arthraxon }\end{array}$ & 11 & 11 \\
& Chrysopogon & 1 & 1 \\
& Dichanthium & 3 & 3 \\
& Erianthus & 9 & 9 \\
& Heteropogon & 1 & 1 \\
& Hyparrhenia & 1 & 2 \\
& Manisuris & 3 & 3 \\
Tripsaceae & Miscanthus & 1 & 2 \\
& Sorghastrum & 2 & 1 \\
& Coix & 1 & 13 \\
& Euchlaena & 1 & 1 \\
& Tripsacum & 3 & 3 \\
\hline
\end{tabular}

were planted in a mixture of equal volumes of perlite and vermiculite; Zea and Euchlaena entries were planted in potting soil. The planting media were subirrigated with Hoagland's Solution No. 1 (9). Germination and seedling growth occurred in a chamber at $27 \mathrm{C}$ under continuous light (cool white fluorescent) at approximately $165 \mu \mathrm{E} \cdot \mathrm{m}^{-2} \cdot \mathrm{sec}^{-1}$ in the 400 to 700 $\mathrm{nm}$ region, as measured with a Lambda Instruments Model LI185 Light Meter equipped with a Model LI-190S Quantum Sensors.

Sampling Extraction, and Spectral Examination. In tests for the presence of dhurrin, most entries were sampled when seedlings had two or three visible leaves. Samples usually consisted of the blades of five first leaves, but for entries with very small seedling leaves, 10 first leaves were used, and for each Zea entry, only three first leaves were taken. Germination of several entries was poor; thus, in several cases samples consisted of the blades of only one or two first leaves. Weighed samples were extracted by autoclaring in water, extracts were diluted in $0.1 N \mathrm{NaOH}$, and spectra were scanned between 250 and 400 nm as previously described (5). A Beckman Model DB-G spectrophotometer was used for scanning spectra, and scans were recorded with a Beckman Model 1005 recorder.

For determination of HCN-p of various parts of indiangrass seedlings at different times after planting, five sets (except as noted) of five Oto seedlings were used at each sampling date, and seedling parts were pooled within sets at each date. Most sampling was confined to seedling shoots, but a few root extracts were assayed. Initial sampling was done when seedlings had only one visible leaf. At this stage the sample consisted of the exposed portion of the leaf blade. When seedlings reached the two-leaf stage, samples consisted of (a) the first leaf excised at its collar, (b) the second leaf excised at the level of the

${ }^{3}$ Mention of a trademark or proprietary product does not constitute a guarantee or warranty of the product by the USDA or the Nebraska Agric. Exp. Stn. and does not imply its approval to the exclusion of other products that may also be suitable. first leaf collar, and (c) the shoot remainder (SR). Similarly, when seedlings reached the three-leaf stage, samples consisted of (a) the first and (b) second leaves excised at their respective collars, (c) the third leaf excised at the level of the second leat collar, and (d) the SR. Samples were extracted, and extracts were diluted in $0.1 \mathrm{~N} \mathrm{NaOH}$ for spectral analysis as previously described (5). All HCN-p values were calculated and expressed as ppm HCN on a fresh weight basis.

Established indiangrass plants, grown in a garden near the University of Nebraska campus, also were sampled as they resumed growth in the spring and early summer of 1978 . These plants were established from ramets taken from an old spaceplanted nursery from a 'Holt' $\times$ Oto cross. Samples, consisting of leaves of young tillers, were subjected to extraction and spectrophotometric assay.

\section{RESULTS AND DISCUSSION}

\section{Assay of Various Species}

As shown in Table 1, 72 entries of grasses representing 39 species, 14 genera, and two tribes were tested for the presence of dhurrin by examination of the absorption spectrum in the range 250 to $400 \mathrm{~nm}$. Only the 13 Sorghastrum entries had well defined peaks in the vicinity of $330 \mathrm{~nm}$, indicating the presence of dhurrin in the seeding leaves. The Euchlaena (teosinte) entry and several of the Zea (corn) entries yield. ed extracts with plateaus or small peaks near $330 \mathrm{~nm}$, but ether extraction, which readily removed $p-\mathrm{HB}$ from the Sorghastrum extracts, did not remove the 330 nm-absorbing material from the Euchlaena and Zea aqueous extracts. Also, an extract of young Zea leaves, prepared by heating the leaves in $95 \%$ ethanol, failed to develop a $330 \mathrm{~nm}$ peak when diluted in $0.1 \mathrm{~N}$ $\mathrm{NaOH}$ at room temperature. This behavior is in contrast to that of dhurrin-containing alcoholic extracts of Sorghum or Sorghastrum seedlings. When diluted in alkali, these dhurrin-containing alcoholic extracts initially displayed the $255 \mathrm{~nm}$ peak that is characteristic of dhurrin; after 1 or 2 hours in base, however, the extracts had lost the dhurrin spectrum, and the spectrum of $p$-HB with a strong absorption maximum at $330 \mathrm{~nm}$ had appeared $(6,10)$. Thus, of the $72 \mathrm{en}$ tries included in this study, only the 13 Sorghastrum representatives contained dhurrin.

The 13 Sorghastrum entries included five cultivars (Holt, 'Llano', 'Nebraska 54', 'Osage', and Oto) and five other accessions (FC37660, FC37882, PI315742, PI315744, and PI315747) of S. nutans, and three accessions (P1310306, PI310307, and PI310308) of S. pellitum. In the initial unreplicated test of these entries, HCN-p values in the vicinity of $1,000 \mathrm{ppm}$ were observed for first seedling leaves of all 13 entries.

Table 2. Caryopsis weight and 11-day seedling height, and length, fresh weight, and HCN-p of first leaf blades of 11-day seedlings of five indiangrass cultivars. Means and standard errors are shown.

\begin{tabular}{|c|c|c|c|c|c|}
\hline \multirow[b]{2}{*}{ Cultivar } & \multirow{2}{*}{$\begin{array}{c}\text { Weight of } \\
25 \text { caryopses } \dagger\end{array}$} & \multirow{2}{*}{$\begin{array}{l}\text { Seedling } \\
\text { height }\end{array}$} & \multicolumn{3}{|c|}{ First leaf blade§ } \\
\hline & & & Length & Fresh weight & HCN-p \\
\hline & $\mathrm{mg}$ & $\ldots$ & - & mg/5 leaves & ppm \\
\hline $\begin{array}{l}\text { Holt } \\
\text { Osage } \\
\text { Nebraska } 54 \\
\text { Oto } \\
\text { Llano }\end{array}$ & $\begin{array}{l}32.8 \pm 0.5 \\
25.3 \pm 0.9 \\
52.8 \pm 1.0 \\
32.4 \pm 1.0 \\
52.8 \pm 0.7\end{array}$ & $\begin{array}{l}68 \pm 4 \\
60 \pm 5 \\
75 \pm 5 \\
70 \pm 2 \\
75 \pm 1\end{array}$ & $\begin{array}{l}18.8 \pm 1.0 \\
15.8 \pm 0.8 \\
18.5 \pm 0.7 \\
17.5 \pm 0.5 \\
17.5 \pm 0.3\end{array}$ & $\begin{array}{l}15.2 \pm 1.0 \\
13.8 \pm 0.8 \\
19.1 \pm 1.4 \\
16.2 \pm 0.8 \\
18.5 \pm 0.6\end{array}$ & $\begin{array}{r}897 \pm 68 \\
1,085 \pm 40 \\
1,127 \pm 46 \\
1,195 \pm 71 \\
1,236 \pm 73\end{array}$ \\
\hline
\end{tabular}

† Each mean was based on eight 25-caryopsis samples. 
Table 3. Influence of seedling age on fresh weight and HCN-p of portions of Oto indiangrass shoots.

\begin{tabular}{|c|c|c|c|c|c|c|c|c|c|c|c|c|c|c|c|c|}
\hline \multirow{3}{*}{$\begin{array}{c}\text { Seedling age } \\
\text { (days after } \\
\text { planting) }\end{array}$} & \multicolumn{8}{|c|}{ Fresh weight of sample $\dagger$} & \multicolumn{8}{|c|}{ HCN-p $†$} \\
\hline & \multicolumn{2}{|c|}{ 1st leaf } & \multicolumn{2}{|c|}{ 2nd leaf } & \multicolumn{2}{|c|}{ 3rd leaf } & \multicolumn{2}{|c|}{ SR $\ddagger$} & \multicolumn{2}{|c|}{ 1st leaf } & \multicolumn{2}{|c|}{ 2nd leaf } & \multicolumn{2}{|c|}{ 3rd leaf } & \multicolumn{2}{|c|}{ SR $\ddagger$} \\
\hline & $\overline{\mathbf{x}}$ & $s_{\bar{s}}$ & $\overline{\mathbf{x}}$ & $s_{\bar{x}}$ & $\overline{\mathbf{x}}$ & $\mathrm{s}_{\overline{\mathbf{x}}}$ & $\overline{\mathbf{x}}$ & $\mathrm{s}_{\overline{\mathbf{x}}}$ & $\overline{\mathbf{x}}$ & $\mathrm{s}_{\overline{\mathbf{x}}}$ & $\overline{\mathbf{x}}$ & $\mathrm{s}_{\overline{\mathrm{x}}}$ & $\overline{\mathbf{x}}$ & $\mathbf{s}_{\overline{\mathbf{x}}}$ & $\overline{\mathbf{x}}$ & $\mathbf{s}_{\overline{\mathbf{x}}}$ \\
\hline & & & & & & & & 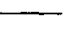 & & & & - & n & & & - \\
\hline $\begin{array}{l}4 \\
5\end{array}$ & $\begin{array}{l}6.8 \\
9.9\end{array}$ & $\begin{array}{l}0.15 \\
0.65\end{array}$ & & & & & & & $\begin{array}{l}1,324 \\
1,232\end{array}$ & $\begin{array}{r}27 \\
8\end{array}$ & & & & & & \\
\hline 6 & 13.9 & 0.82 & & & & & & & 1,108 & 55 & & & & & & \\
\hline 7 & 13.3 & 0.44 & 4.1 & 0.29 & & & & & 1,189 & 43 & 1,206 & 92 & & & & \\
\hline 8 & 13.7 & 0.58 & 4.4 & 0.35 & & & 6.9 & 0.38 & 1,254 & 84 & 929 & 77 & & & 618 & 46 \\
\hline 9 & 15.2 & 0.68 & 6.7 & 0.49 & & & 8.9 & 0.57 & 1,131 & 38 & 631 & 60 & & & 396 & 18 \\
\hline 11 & 13.9 & 0.56 & 17.1 & 0.70 & & & 12.1 & 0.17 & 1,235 & 40 & 643 & 94 & & & 382 & 34 \\
\hline 13 & 15.2 & 0.71 & 27.2 & 0.59 & & & 15.4 & 0.62 & 1,369 & 59 & 553 & 46 & & & 362 & 12 \\
\hline 15 & 11.8 & 0.83 & 29.4 & 1.28 & 6.1 & 1.26 & 24.2 & 1.22 & 1,506 & 39 & 699 & 23 & 763 & 23 & 368 & 20 \\
\hline 19 & 14.1 & 0.59 & 36.7 & 0.92 & 21.9 & 3.08 & 38.4 & 1.56 & 1,382 & 70 & 694 & 33 & 605 & 32 & 258 & 11 \\
\hline
\end{tabular}

† Values are means of two five-shoot samples at 4 and 5 days, and five five-shoot samples at each of the other seedling ages. HCN-p values are expressed on a fresh weight basis. $\quad \mathrm{SR}=$ remainder of the shoot.

\section{Assay of Indiangrass Cultivars}

The five indiangrass cultivars listed in the preceding paragraph were compared in a test with four replications. Each replication included a sample of the blades of five first leaves of 11-day-old seedlings of each cultivar. Height of the sampled seedlings, and length, weight, and HCN-p of the leaf blade samples were determined. Caryopsis weight also was determined for each cultivar. As shown in Table 2, caryopsis weight for Llano and Nebraska 54 was about double that for Osage, and weights for Holt and Oto were about equal and were intermediate in magnitude. Caryopsis weight was positively correlated with seedling height ( $r=0.91$, significant at the 0.05 level), based on the five pairs of means obtained for these traits (Table 2). Caryopsis weight also was positively associated with weight of the first leaf blade ( $\mathrm{r}=$ 0.97 , significant at the 0.01 level), but not with length of this leaf blade, nor with HCN-p. As expected on the basis of their significant correlations with caryopsis weight, seedling height and first leaf blade weight were correlated ( $r=0.95$, significant at the 0.05 level). Of the five cultivars tested, Holt was lowest in HCN-p; differences in HCN-p among the other four cultivars were not significant. HCN-p level was not closely associated with any of the other traits whose measurements are shown in Table 2.

\section{Variation of HCN-p With Age and Shoot Portion}

Several experiments were done on the influence of seedling age and shoot portion on HCN-p. Results were similar across experiments; thus, the results of only one such experiment will be presented. As shown in Table 3, first leaves of Oto seedlings had attained their maximum fresh weight within about 6 days after planting. Samples of first leaves taken between 6 and 19 days varied somewhat in fresh weight, but differences were generally not large. By the 7 th day after planting, it was possible to harvest second leaves. In contrast to first leaves, second leaves increased appreciably in fresh weight between days 7 and 19. Similarly, fresh weights of the shoot remainder (SR) increased steadily and substantially between days 8 and 19. Third leaves were sampled on days 15 and 19; the 19-day samples were more than three times as heavy as the 15-day samples.

As shown in Table 3, HCN-p values for the various shoot portions indicated that first leaves were relatively high in HCN-p and that, as previously observed for Sorghum seedlings (5), values for first leaves remained quite uniform over a considerable span of seedling age. The HCN-p for second leaves dropped appreciably during early expansion of these leaves, but after about day 9 , values were uniformly about half as great as those for first leaves. A decline in HCN-p of third leaves also accompanied early expansion of such leaves. The SR was lower in HCN-p than any of the leaf samples from the same seedlings, and HCN-p tended to decline as the fresh weight of this portion increased.

Extracts of the various shoot portions all had well. defined absorption maxima at $330 \mathrm{~nm}$, as illustrated

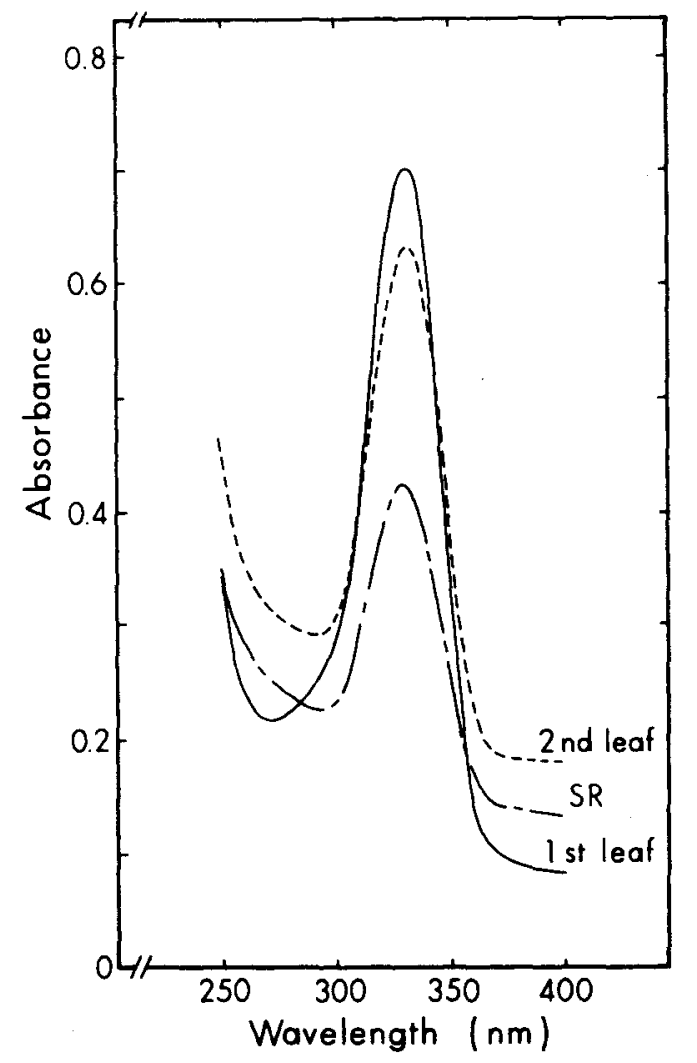

Fig. 1. Absorption spectra of extracts of first leaves, second leaves, and remainders of shoots (SR) from 11-day seedlings of Oto indiangrass. Extracts were diluted in $0.1 \mathrm{~N} \mathrm{NaOH}$. 


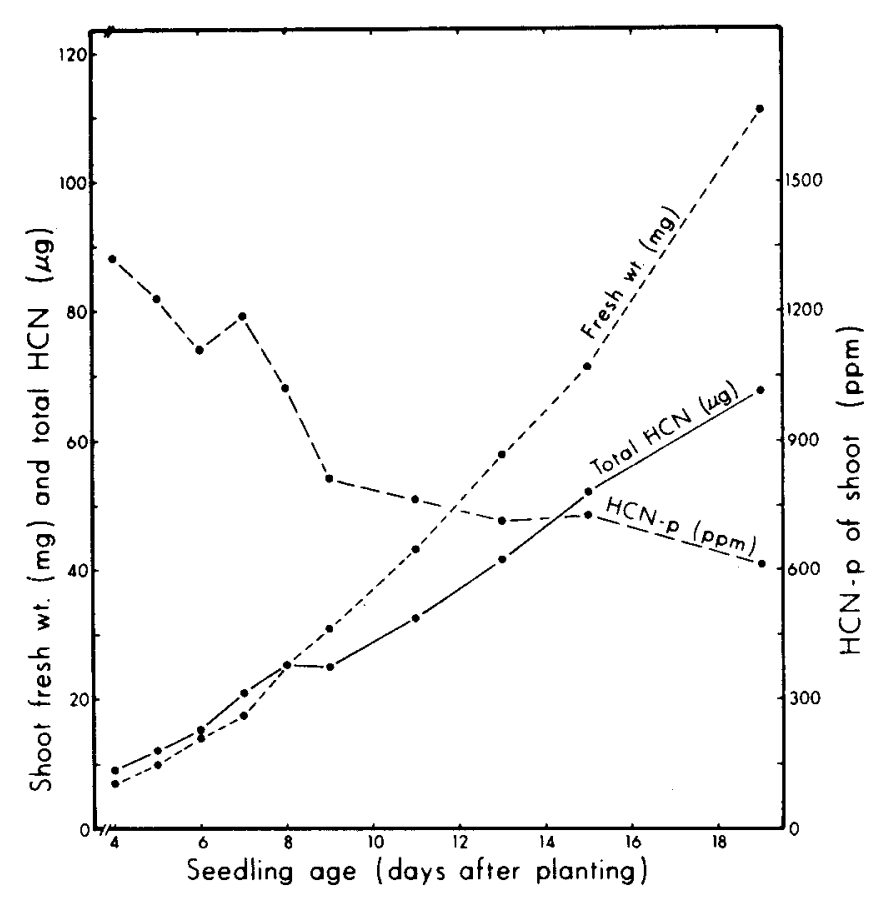

Fig. 2. Fresh weight (five shoots), total HCN (five shoots), and HCN-p of Oto indiangrass shoots of various ages.

in Fig. 1. First leaves had lower concentrations of extraneous absorbing substances than the other shoot portions, as indicated by the relatively low absorption of first leaf extracts above $350 \mathrm{~nm}$ and below $300 \mathrm{~nm}$ (Fig. 1). Extracts of roots from 8 and 19-day seedlings also were scanned, and each had a definite absorption peak at $330 \mathrm{~nm}$. Thus, it appeared that dhurrin was present in the seedling roots as well as the shoots, but concentrations in the roots were relatively low, ranging from 100 to $200 \mathrm{ppm}$.

From the data in Table 3, total shoot fresh weights and total HCN contents $(\mu \mathrm{g})$ of shoots were calculated, and values of HCN-p (ppm) for entire shoots were then calculated. As shown in Fig. 2, following day 8 total shoot weight increased relatively more rapidly than total HCN content. Therefore, HCN-p values for the entire shoot declined with advancing seedling age. Additional calculations based on the data in Table 3 revealed that beginning with day 8 , first leaves consistently accounted for a greater percentage of the shoot's HCN than of its fresh weight, whereas the SR consistently contributed a lower percentage of HCN than of weight. Second and third leaves contributed roughly the same percentage of $\mathrm{HCN}$ as of fresh weight in this experiment.

\section{Extracts of Tillers From Established Plants}

On seven occasions between 11 May and 21 July, 1978 , young tillers were harvested from each of five vigorous field-grown indiangrass plants. Leaf extracts were prepared, and spectra were scanned as for seedling samples. Some of the tiller extracts had a welldefined $330 \mathrm{~nm}$ absorption maximum; other extracts of apparently similar tillers lacked this peak. The frequency with which the $330 \mathrm{~nm}$ peak was observed decreased as the season advanced. Based on $A_{330}$ read-

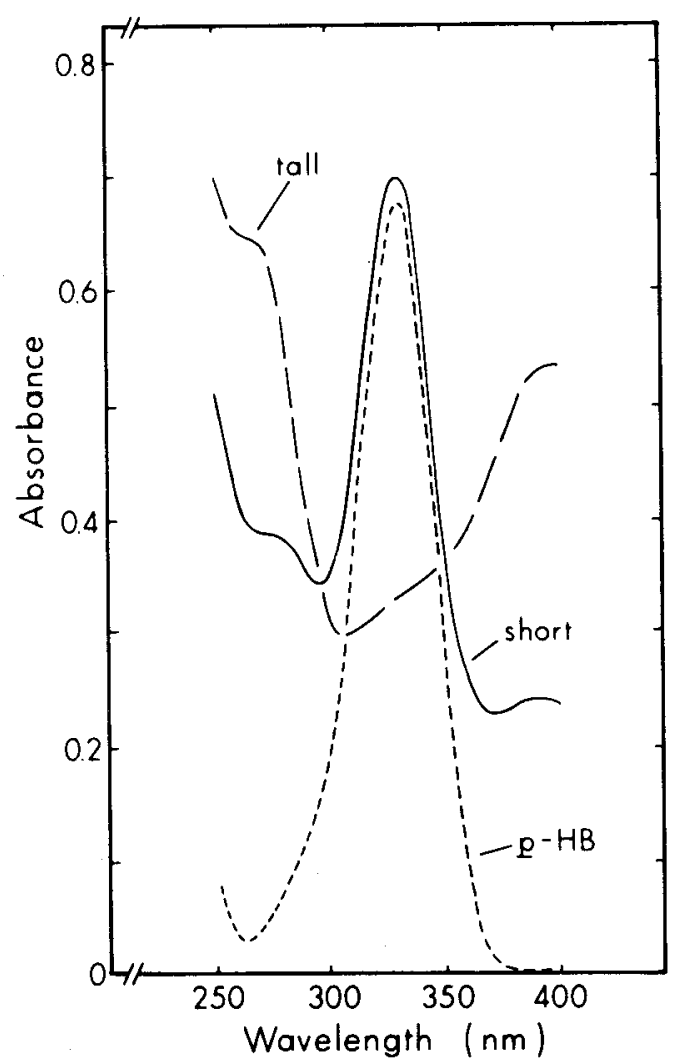

Fig. 3. Absorption spectra of extracts of young leaves from two tillers from an established indiangrass plant. Tiller heights: short $-16 \mathrm{~cm}$; tall $-31 \mathrm{~cm}$. Extracts were diluted in $0.1 \mathrm{~N} \mathrm{NaOH}$. The spectrum of a solution of $p$-hydroxy. benzaldehyde $(p-H B)(3 \mu \mathrm{g} / \mathrm{ml})$ in $0.1 \mathrm{~N} \mathrm{NaOH}$ is shown for comparison.

ings of those extracts with the peak, it was calculated that some tillers had HCN-p values in the 200 to 400 ppm range. As shown in Fig. 3, it was not uncommon for two young tillers, harvested from a single plant on the same day, to have greatly different spectra. $\mathrm{Al}$ though the spectral evidence clearly pointed to the presence of dhurrin in young tillers of indiangrass, results indicated that in indiangrass, as in Sorghum (7), tiller extracts contained more interferring sub. stances than were found in seedlings.

The HCN-p levels in indiangrass seedlings were in the same range as values for Sorghum seedlings that are considered to be high in HCN-p (5). Although the danger of grazing livestock on Sorghum under some conditions is well recognized, we know of no re. ports of livestock loss resulting from the grazing of indiangrass. We suggest that the absence of loss on indiangrass may be a result of the fact that this grass is nearly always grazed in pastures containing a mix. ture of species, whereas Sorghum is usually grazed in pure stands. Also, warm-season pastures usually are not grazed until the plants are past the stage when highest HCN concentration would be expected.

\section{REFERENCES}

1. Akazawa, T., P. Miljanich, and E. E. Conn. 1960. Studies on cyanogenic glycoside of Sorghum vulgare. Plant Physiol. 35:535-538. 
2. Conn, E. E. 1978. Cyanogenesis, the production of hydrogen cyanide, by plants. p. 301-310. In Keeler, R. F., K. R. Van Kampen, and L. F. James (eds.). Effects of poisonous plants on livestock. Academic Press, Inc., N. Y.

3. Dunstan, W. R., and T. A. Henry. 1902. Cyanogenesis in plants. II. The great millet Sorghum vulgare. Phil. Trans. Royal Soc. (London) Ser. A 199:399-410.

4. Fat, L. T. S. 1977. Contribution to the knowledge of cyanogenesis in angiosperms. Koninklijke Nederlandse Akademie van Wetenschappen, Amsterdam, Series C 80:227-237.

5. Gorz, H. J., W. L. Haag, J. E. Specht, and F. A. Haskins. 1977. Assay of $p$-hydroxybenzaldehyde as a measure of hydrocyanic acid potential in sorghums. Crop Sci. 17:578-582.

6. - - F. A. Haskins, Richard Dam, and K. P. Vogel. 1979
Dhurrin in Sorghastrum nutans. Phytochemistry (In press).

7. Haskins, F. A., H. J. Gorz, and R. L. Nielsen. 1979. Comparison of the hydrocyanic acid potential of Sorghum seedlings and tillers. Agron. J. 71:501-504.

8. Hitchcock, A. S., and Agnes Chase. 1950. Manual of the grasses of the United States, 2nd edition. USDA Misc. Publ. No. 200.

9. Hoagland, D. R., and D. I. Arnon. 1950. The water-culture method for growing plants without soil. California Agric. Exp. Stn. Circ. 347 (revised).

10. Mao, C.-H., and Laurens Anderson. 1965. Cyanogenesis in Sorghum vulgare. II. Mechanism of the alkaline hydrolysis of dhurrin ( $p$-hydroxymandelonitrile glucoside). J. Org. Chem. 30:603-607. 